\title{
Letter-to-the-Editor
}

\section{Asymetric Testicular Schistosomal Infection}

\author{
Daniel Abensur Athanazio ${ }^{1}$ and Paulo Roberto Fontes Athanazio ${ }^{1,2}$ \\ ${ }^{1}$ Federal University of Bahia; ${ }^{2}$ Departament of Pathology, Edgard Santos Hospital; Salvador, BA, Brazil
}

We read with great interest the recent report of testicular schistosomiasis in this journal. The authors reported the case of a 31-year-old man from Northeast Brazil presenting a $2 \mathrm{~cm}$ nodule in the right testis, with proven Schistosoma mansoni infection and associated granulomatous inflammation documented by excisional biopsy. The authors suggested the presence of eggs results from venous channels between the internal spermatic and mesenteric veins [1].

In Edgard Santos Hospital, Salvador, Brazil, we documented a rare (first report) case of spontaneous aortocutaneous fistula complicating the natural history of a thoracoabdominal aortic aneurysm [2]. Additional diagnoses were a benign schwannoma of the anterior chest wall and Schistosoma mansoni infection detected by the presence of viable eggs in liver and large bowel wall, and mostly calcified eggs in lungs and testes. Strikingly, the egg load was massive in the right testis (with a mean count of 12 per 10x objective) while only sparse calcified eggs were detected in the left testis ( $<1$ per 10x objective) as illustrated in Figure 1.

Such asymmetry is most probably a manifestation, as suggested by Lopes et al. [1], that egg deposition in tests may reflect the availability of portosystemic anastomosis. Egg deposition in testicular tissue may not require any anatomical variation since the posterior vein to the spermatic chord (cremasteric vein) drains into epigastric veins. Similar to what can be observed for isolated varicocele that may represent a salvage pathway for portal hypertension in patients with other unilateral portosystemic shunts in the triple testicular blood drainage [3], such variations may also explain asymmetric infection load in patients with S.mansoni-related portal hypertension. This determining factor for egg load may indeed define which patients may develop large lesions that may clinically present as testicular nodules.

\section{References}

1. Lopes R.I., Leite K.R., Prando D., Lopes R.N. Testicular schistosomiasis caused by Schistosoma mansoni: a case report from Brazil. Brazilian Journal of Infectious Diseases 2007;11:523-4.

2. Athanazio D.A., Athanazio P.R.F., Schaer-Barbosa H. Aortocutaneous fistula complicating a pseudoaneurysm of the thoracic aorta - a necropsy report. Cardiovascular Pathology 2007; 16:357-8.

3. Pinggera G.M., Herwig R., Pallwein L., et al. Isolated right-sided varicocele as a salvage pathway for portal hypertension. Int $\mathrm{J}$ Clin Pract 2005;59:740-2.

Figure 1. Massive egg load in the right testis (A), and sparse calcified eggs in the left testis ( $<1$ per 10x objective).
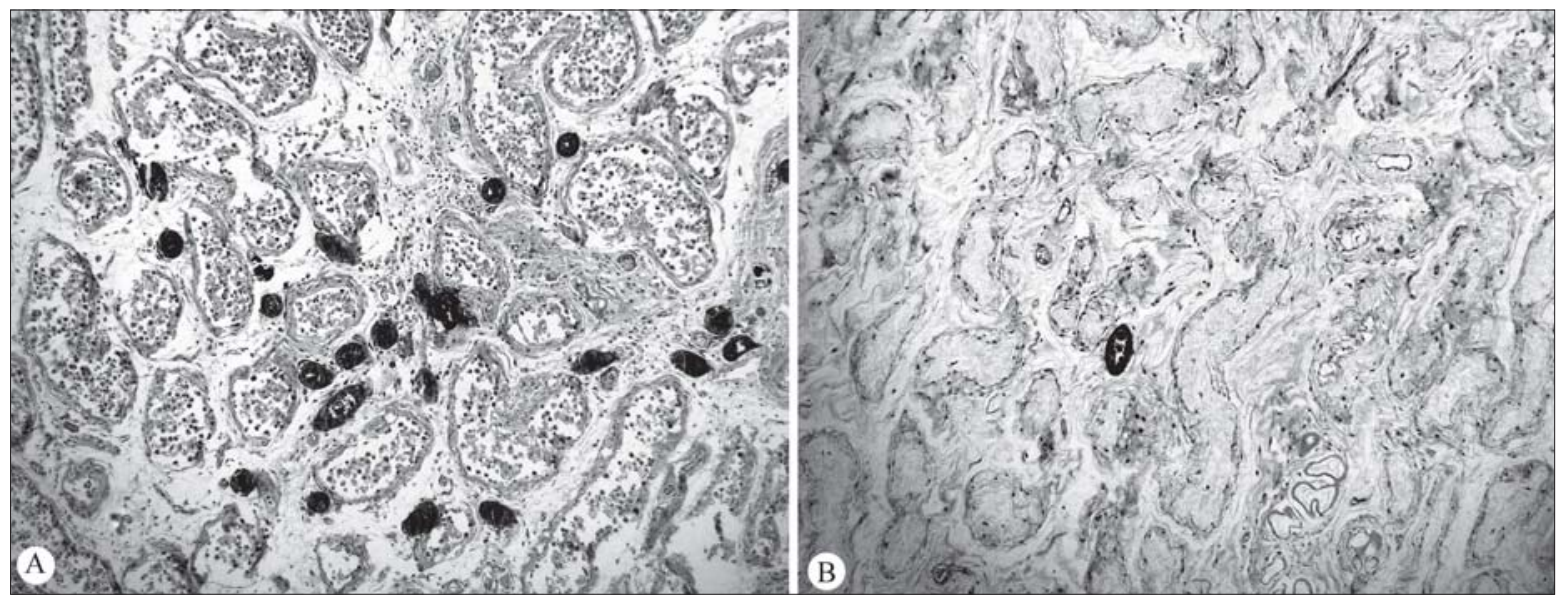

Address for correspondence: Dr. Daniel Abensur Athanazio. Departamento de Biointeração - ICS - UFBA. Av. Reitor Miguel Calmon s/nº - Campus do Canela. Zip code: 40.110-100 Salvador - Bahia - Brazil. Phone: (71) 3245-8602 Fax: (71) 3240-4194. E-mail: daa@ufba.br.

The Brazilian Journal of Infectious Diseases 2008;12(6):461.

(C) 2008 by The Brazilian Journal of Infectious Diseases and Contexto Publishing. All rights reserved. 